\title{
Moral Normative Force and Clinical Ethics Expertise
}

Brummett and Salter propose a useful and timely taxonomy of clinical ethics expertise (2019). As the field becomes further "professionalized" this taxonomy is important, and the core of it is right. It needs some refinement around the edges, however. In their conclusion, Brummett and Salter rightly point out that there is a significant difference between the ethicist whose recommendations are procedure- and process-heavy, consensus-driven, and dialogical and the authoritarian ethicist whose recommendations flow from "private moral views" (Brummett and Salter, 2019). This admission doesn't go far enough. Brummett and Salter's taxonomy fails to capture the notion that offering recommendations whose normative force is moral is different in kind from recommendations whose normative force is non-moral, such as those recommendations that are free of moral content or justified by convention. The difference is in kind, not scale. I argue further that clinical ethics expertise, if possible, consists at least in offering recommendations whose normative force is moral. These two claims imply that the taxonomy fails to cut clinical ethics expertise at the joints: the ethicist who offers justified nonmoral normative recommendations is a different kind of ethicist from the one who offers justified moral normative recommendations, yet both are categorized as clinical ethics experts. I finish by offering a refinement of the taxonomy that more precisely categorizes clinical ethicists.

Brummett and Salter's taxonomy starts by answering the question, "Can clinical ethicists offer justified normative recommendations in active patient cases?" At a general level, we can make a distinction between conventional norms and moral norms. What separates moral norms from conventional norms is that, unlike conventional norms such as norms associated with etiquette, moral norms exhibit distinctive features such as universal applicability and independence from authority (Nichols, 2004; Huebner, Lee, and Hauser, 2010). Children begin 
making the distinction between the conventional and the moral very early in their development (Nichols, 2004). Importantly, these are not the same type of norm on either ends of a scale. The norm that one ought to not burp in public is different in kind from the norm that one ought to not harm another person.

Conventional norms are of course prevalent in medicine generally and hospitals specifically. Norms relating to the building of consensus arguably are conventional, as there is no logical relation between agreement among a group of people and morally right action (except the relation of inequality). But there are also multiple types of normativity that might be involved in making clinical recommendations. Clinical ethicists often make recommendations embedding epistemic normativity, such as prescriptions for what the team ought to believe given the evidence or prescriptions for what evidence ought to be gathered. For examples, ethicists might recommend that the patient's decisional capacity should be assessed or that the treating team should take no irreversible action until the patient's condition "declares" itself. Ethicists might also make recommendations embedding political prescriptions, such as those prescriptions that hospital policies generate. Prescriptions might also be merely practical. Or, they might be moral: withdrawal of treatment is permissible because it's permissible to withhold treatment and withdrawal and withholding are morally equivalent; the physician is obligated to stop CPR because it will only harm the patient; the physician may not compel treatment for a patient who is competently and capably refusing that treatment.

These are all different kinds of normativity. The moral/conventional distinction offers one way to distinguish them; unlike conventional norms, moral norms are universally applicable and authority-independent. But there are other differences. Epistemic, political, and practical prescriptions are all goal-oriented: if you want to achieve some aim (e.g., having true beliefs, following hospital policy, discharging the patient), then you should do this or do that. But moral 
prescriptions may not be necessarily goal-oriented. Furthermore, moral prescriptions, but not other kinds of prescriptions, embed terms relating to or derived from fundamental moral values such as pleasures, pains, harms, benefits, duties, virtues, boo and yay. But other prescriptions need not embed moral values at all.

Given that there are different kinds of normativity, recommendations have different normative force. Recommendations that one ought to believe something or gather evidence have epistemic normative force; recommendations to have a family meeting have practical normative force; recommendations to refuse a patient's request for ECMO have moral normative force. Although all of these recommendations are in the proper domain of a clinical ethicist, only those recommendations whose normative force is moral are the mark of the ethicist. If what 'clinical ethicist' refers to is any different than what 'clinical proceduralist' or 'clinical consensus builder' refers to, it must refer to the person who makes clinical recommendations whose normative force is moral.

The notions that there are different kinds of normativity and that clinical ethicists are those people who make clinical recommendations whose normative force is moral highlight an incompleteness of Brummett and Salter's taxonomy. Consider a person whose recommendations are entirely procedure-focused, consensus-dominated, process-heavy, justified by conventional norms, and communicated dialogically. The normative force of the recommendation is conventional, stemming from hospital policies and how they are followed. Indeed, given that the recommendation is dominated by consensus, it's a stretch to say that it is even the ethicist's recommendation rather the other parties to consensus or the authors of the policy. This is not the profile of an expert in clinical ethics. Anyone suitably situated in the hospital hierarchy with good knowledge of hospital policy and open channels of communication can make such recommendations. That is, it could be a nurse manager, risk manager, a social worker with years 
of experience, a physician with no additional training in ethics, or any number of people who have never heard of Kant or Mill (much less Timmons), the Belmont Report, or the ASBH's HEC-Cs. But such a person would count as an expert clinical ethicist, according to Brummett and Salter's taxonomy.

Contrast this person with the person who takes in a consult, gathers all of the relevant information from the relevant people, writes a note in the patient's chart detailing a recommended course of action based on how the medical facts interact with moral philosophy, then communicates that recommendation to the treatment team. This is a different kind of recommendation - a different kind of expertise - and the difference lies in the normative force of the recommendation.

A proper taxonomy ought to account for this difference in kind. Brummett and Salter's taxonomy is close to properly parsing clinical ethics expertise. There are multiple ways the taxonomy might be revised. The first distinction in their taxonomy is whether clinical ethicists can make justified normative recommendations at all. My suggestion is to parse ethicists by kind of normative force at the next level of distinction. If one answers 'Yes' to the first question, branching out to the Positive Views, the second question ought to be, "Can the person make recommendations whose normative force is moral?" If the answer is 'Yes', then it may be appropriate to consider the person a clinical ethics expert and categorize them further according to Brummett and Salter's existing taxonomy. If the answer to that second question is 'No,' then although the person ought not be considered a clinical ethics expert, they still may make justified normative recommendations. It is possible that the answer to the second question will always be 'No,' in which case there would be no experts in clinical ethics, but still people who can make justified normative recommendations. 
However, a negative answer to this second question does not imply a negative answer to the first question. While some people might not be able to offer justified clinical recommendations with moral normative force, they might still be able to offer justified clinical recommendations whose normative force is non-moral, such as those people who make recommendations with purely epistemic, political, or conventional normative force. One might agree that there are some justified normative recommendations, which branches out to the Positive View, but that the normative force of these recommendations is non-moral, which is a branch distinct from those ethicists whose recommendations have moral normative force. In other words, there ought to be two branches out of the Positive Views, one branch that includes those people whose recommendations have moral normative force (experts) and one branch that includes those people whose recommendations have non-moral normative force.

Being able to make recommendations whose normative force is moral is necessary for being an expert in clinical ethics, though it is not sufficient. As any clinical ethicist can attest, doing clinical ethics involves a much wider range of skills. And as the field becomes further professionalized, it is equally important to note that although obtaining the HEC-C may suffice for clinical ethics competence, obtaining the HEC-C does not impart upon one the ability to make recommendations whose normative force is moral. Thus, obtaining the HEC-C does not suffice for expertise in clinical ethics. It is a further question whether being able to make recommendations whose normative force is moral is also necessary for competence in clinical ethics.

\section{References}

Brummett A. and Salter E. 2019. Taxonomizing Views of Clinical Ethics Expertise. American Journal of Bioethics.

Huebner B, Lee J, and Hauser M. 2010. The Moral-Conventional Distinction in Mature Moral Competence. Journal of Cognition and Culture 10 (1-2): 1-26. 
Penultimate draft: Please cite final version in American Journal of Bioethics

Nichols S. 2004. Sentimental Rules: On the Natural Foundations of Moral Judgment. Oxford: Oxford University Press. 